This document is confidential and is proprietary to the American Chemical Society and its authors. Do not copy or disclose without written permission. If you have received this item in error, notify the sender and delete all copies.

\title{
Stimuli-responsive co-delivery of oligonucleotides and drugs by self-assembled peptide nanoparticles
}

\begin{tabular}{|r|l|}
\hline Journal: & Biomacromolecules \\
\hline Manuscript ID & bm-2015-01614b.R1 \\
\hline Manuscript Type: & Article \\
\hline Date Submitted by the Author: & $12-$ Feb-2016 \\
\hline Complete List of Authors: & $\begin{array}{l}\text { Sigg, Severin; University of Basel, Department of Chemistry } \\
\text { Postupalenko, Viktoriia; University of Basel, Department of Chemistry } \\
\text { Duskey, Jason; University of Basel, Department of Chemistry } \\
\text { Palivan, Cornelia; University of Basel, Chemistry Department } \\
\text { Meier, Wolfgang; University of Basel, Department of Chemistry }\end{array}$ \\
\hline
\end{tabular}

\section{SCHOLARONE \\ Manuscripts}




\title{
Stimuli-responsive co-delivery of oligonucleotides
}

\section{and drugs by self-assembled peptide nanoparticles}

\author{
Severin J. Sigg, Viktoriia Postupalenko, Jason T. Duskey, Cornelia G. Palivan, Wolfgang Meier*
}

Department of Chemistry, University of Basel, Klingelbergstrasse 80, CH-4056 Basel, Switzerland

KEYWORDS

Peptide nanoparticles, stimuli-responsive, co-delivery of drugs and AONs

\begin{abstract}
Ever more emerging combined treatments exploiting synergistic effects of drug combinations demand for smart, responsive co-delivery carriers to reveal their full potential. In this study, a multifunctional stimuli-responsive amphiphilic peptide was designed and synthesized to selfassemble into nanoparticles capable of co-bearing and -releasing hydrophobic drugs and antisense oligonucleotides (AONs) for combined therapies. The rational design was based on a hydrophobic L-tryptophan-D-leucine repeating unit derived from a truncated sequence of gramicidin A (gT), to entrap hydrophobic cargo, which is combined with a hydrophilic moiety of histidines to provide electrostatic affinity to nucleotides. Stimuli-responsiveness was implemented by linking the hydrophobic and hydrophilic sequence through an artificial amino acid bearing a disulfide functional group (H3SSgT). Stimuli-responsive peptides self-assembled
\end{abstract}


in spherical nanoparticles in sizes $(100-200 \mathrm{~nm})$ generally considered as preferable for drug delivery applications. Responsive peptide nanoparticles revealed notable nucleotide condensing abilities while maintaining the ability to load hydrophobic cargo. The disulfide cleavage site introduced in the peptide sequence induced responsiveness to physiological concentrations of reducing agent, serving to release the incorporated molecules. Furthermore, the peptide nanoparticles, singly loaded or co-loaded with boron-dipyrromethene (BODIPY) and/or AONs, were efficiently uptaken by cells. Such amphiphilic peptides that led to non-cytotoxic, reductionresponsive nanoparticles capable of co-delivering hydrophobic and nucleic acid payloads simultaneously provide potential towards combined treatment strategies to exploit synergistic effects.

\section{INTRODUCTION}

Combined treatments are gaining increasing impact in medicine to exploit synergistic effects of therapeutics but also to overcome multi drug resistance (MDR) in cancer therapies ${ }^{1}$. This creates a tremendous demand for sophisticated carriers systems capable of co-delivering therapeutics simultaneously for higher efficacy. For this purpose not only combinations of small drugs are beneficial but also drug/gene combinations are of high interest, especially in the case of P-glycoprotein (P-gp) mediated MDR. ${ }^{1}$ Nanotechnology provides a vast array of opportunities and promise in the rational design of multifunctional drug delivery systems. Nanocarriers can be designed for the delivery of therapeutics: protecting them from being metabolized $^{2,3}$, enhancing bioavailability, lowering off-target effects, and decreasing the necessary drug dose by increasing accumulation at the diseased site. ${ }^{4}$ Of particular interest for P-gp mediated MDR is the co- 
delivery of drugs and nucleic acids in a single nanocarrier system. Promising results were obtained by AON-mediated down-regulation of the over expressed P-gp, responsible for drug efflux, in combination with small molecule anti-cancer drugs. ${ }^{5,6}$ For incorporation of payloads two main strategies are followed, where nucleic acids or drugs are either synthetically conjugated to the carrier or non-covalently condensed or entrapped. ${ }^{2,7}$ Covalent strategies involve the linkage of polymers, proteins, peptides, and inorganic nanoparticles to nucleic acids or drugs, ${ }^{8}$ while non-covalent condensation is achieved via electrostatic interaction, hydrogen bonding, and hydrophobic interactions. Non-covalent nanocarriers for oligonucleotide delivery are usually able to cross cell membranes and deliver the cargo better than conjugated ones, but are in general more difficult to control ${ }^{7,9}$. Current strategies for co-delivery of small molecule drugs and nucleic acids rely on lipids ${ }^{10,11}$, polymers ${ }^{12,13}$, and conjugates ${ }^{14,15}$, which form structures able to entrap small drugs as well as to non-covalently condense DNA or RNA. Further improvement of efficacy can be achieved by utilizing physiological microenvironments at pathological sites such as $\mathrm{pH}^{16-19}$, temperature ${ }^{20}$, and redox potential ${ }^{21,22}$ as release triggers. Responsive polymeric systems and conjugates for co-delivery were developed recently, bearing moieties sensitive to physiological triggers such as $\mathrm{pH}^{23-26}$ or redox potential ${ }^{27-30}$.

Emerging peptide based self-assembled nanostructures in the field of nanomedicine are particularly interesting because they are considered to be inherently biocompatible and biodegradable ${ }^{31-33}$. Specific inter- and intramolecular interactions between amino acids such as electrostatic interactions, hydrogen-bonding, hydrophobic interactions, and $\pi$ - $\pi$-stacking can be implemented to obtain highly ordered and defined assemblies. The bottom up rational design is based on selecting amino acids with the desired properties in order to create novel amphiphilic peptides able to self-assemble into defined architectures (micelles ${ }^{34,35}$, vesicles ${ }^{31,36,37}$, fibers ${ }^{38}$ 
and other nanoparticles ${ }^{39,40}$ ). Furthermore, the combination of distinct functionalities, such as responsiveness, can be implemented within one molecule enabling the development of peptides self-assembling into well-defined and multifunctional nanoparticles, which is a tremendous advantage due to simplicity and applicability for biomedical applications ${ }^{41-43}$. Reported peptidic carriers for delivering a single drug comprise polyplexes ${ }^{44-46}$, hydrogels ${ }^{47}$, and micelles ${ }^{42,43,48-50}$. There are only a few peptidic co-delivery systems described to date capable of delivering nucleic acids and small molecule drugs simultaneously ${ }^{42,49,50}$. Recent reports describe peptides, consisting of a polyhistidine-polylysine hydrophilic peptide sequence coupled with a hydrophobic sequence comprised of alanine, phenylalanine and/or leucine, which show synergistic cytotoxic effects when delivering p53 plasmid in combination with doxorubicin (Dox) or paclitaxel $(\mathrm{PTX})^{49,50}$. Another report describes a slow release (20-30 hours) of Dox from a polyhistidine-TAT conjugate at $\mathrm{pH} 5$ compared to neutral $\mathrm{pH}$ accompanied by synergistic effects when co-delivered with p53 plasmid $^{42}$. However, further improvement for stimuli responsiveness is essential to enhance a rapid delivery and/or release of co-loaded payloads.

Recently, we reported amphiphilic peptides based on a hydrophobic region (region 3, Figure 1) consisting of a truncated gramicidin A (gT) sequence ${ }^{51,52}$, combined with a short hydrophilic sequence which can form micelles ${ }^{34,}{ }^{35}$ fibers $^{34}$, vesicles ${ }^{53}$ and peptide nanoparticles ${ }^{40}$. Combination of gT part with acetylated lysines (AcX3gT) leads to their assembly into peptide nanoparticles. They showed embedding of hydrophobic and hydrophilic payloads and can form ordered gold nanoparticle superstructures ${ }^{39}$. The multi compartment micellar (MCM) inner structure of the nanoparticles ${ }^{54}$ provides similar volume fractions for hydrophilic and hydrophobic payload but lacking sites for nucleic acid condensation and stimuli-triggered release mechanisms. 
Here we aim for a straightforward rational design of new peptide nanoparticles that enhance the properties of the AcX3gT nanoparticles to favor co-delivery and rapid release of small molecule drugs and nucleic acids simultaneously by reduction-responsiveness. The new peptides are separated into three key structural features: the hydrophilic part (region 1), linker unit (region 2), and hydrophobic part (region 3) (Figure 1). The hydrophilic moiety was redesigned from the previous peptide AcX3gT by implementing nucleotide condensing sites, based on oligo histidine, known to promote these interactions. ${ }^{55}$ By introducing oligo histidine the slight surface charge is in addition intended to prevent aggregation, which limited AcX3gT potential use, ${ }^{40}$ when loaded with hydrophobic molecules. Moreover, using oligo histidine as hydrophilic part preserves secondary aggregation to nanoparticles due to a $\mathrm{pKa}$ of 6.0 in contrast to earlier reported nonacetylated $\mathrm{K} 3 \mathrm{gT}$, bearing lysines with a $\mathrm{pKa}$ of 10.7 , which are forming micelles. ${ }^{35}$

Increasing the number of aromatic side chains is expected to support molecules incorporation as already reported for AcX3gT. The nanoparticles were also expected to be smaller, thus more suitable for biomedical applications due to higher water solubility compared to AcX3gT. ${ }^{35,54}$ The stimuli-responsiveness to cellular redox potential was integrated to the sequence by using an artificial disulfide amino acid (region 2, Figure 1). By adding this linker in-between the hydrophilic and hydrophobic sequences, we favor a higher release upon external stimuli, which was previously not available when designed only with peptide bonds. Therefore, in the structure of this new peptide, only the gramicidin inspired seven amino acid repeating unit gT remained from the earlier reported peptide AcX3gT in order to maintain the previously observed selfassembly into nanoparticles that are capable of entrapping hydrophobic payloads. Characterization revealed that the three functional units enabled assembly of spherical peptide nanoparticles that were reduction sensitive $(\mathrm{H} 3 \mathrm{SSgT})$ and capable of loading desired model drug 
(boron-dipyrromethene (BODIPY)) and nucleic acid (antisense oligonucleotide (AON)) payloads simultaneously. We selected BODIPY as model molecule with the appropriate hydrophobicity and molecular weight, whilst the hydrophilic DoxHCl served only to demonstrate the ability of the peptide nanoparticles to encapsulate hydrophilic molecules as well. Fluorescence correlation spectroscopy (FCS) analysis was used to evaluate whether the reduction responsive particles were able to rapidly release all payloads in a reducing environment. A final analysis in HeLa cells was performed to show that the reduction-sensitive $\mathrm{H} 3 \mathrm{SSgT}$ peptide nanoparticles are uptaken and the cargo retain its functionality. Although stimuli-responsive co-delivery architectures have been developed for polymer, lipid, and peptide-conjugate self-assemblies our strategy has the advantage of providing purely peptidic and biodegradable nanoparticles for efficient co-delivery and release of oligonucleotides and drugs simultaneously upon reduction.

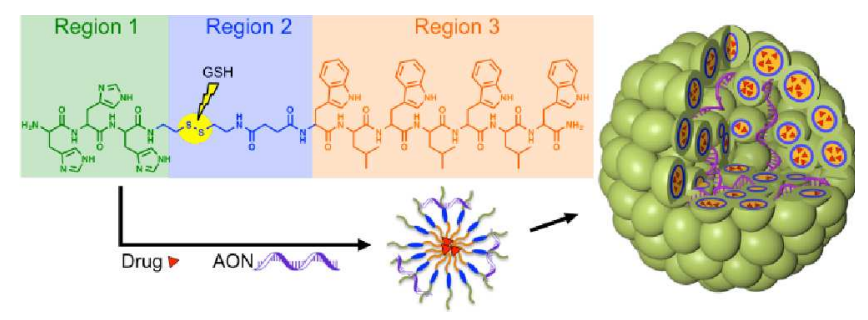

Figure 1. Schematic representation of nanoparticle assembly. Designed amphiphilic peptide consists of three regions: hydrophilic (region 1), reducible linker (region 2), and hydrophobic (region 3). Amphiphilic peptides assemble in a first step into micelles, incorporating drug in the hydrophobic part and nucleotides along their hydrophilic part. Further self-assembly leads to spherical nanoparticles, potentially multicompartment micelles. ${ }^{54}$ Adapted from Gunkel-Grabole et al. ${ }^{56}$ - Reproduced by permission of The Royal Society of Chemistry. 


\section{MATERIALS AND METHODS}

Materials. All reagents and materials were of the highest commercially available grade and used without further purification, unless otherwise mentioned. Rink Amide AM resin (0.71

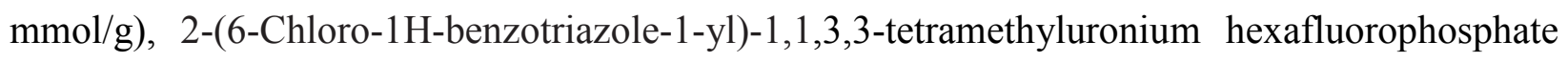
(HCTU) and Fmoc-Trp(Boc)-OH were obtained from IRIS Biotech GmbH. Boc-Cystamine-Suc$\mathrm{OH}$ was purchased from IRIS Biotech $\mathrm{GmbH}$ and converted into Fmoc-Cystamine-Suc-OH amino acid as described previously ${ }^{57}$. All other amino acids were purchased from Novabiochem. Dimethylformamide (DMF) was obtained from J.T. Baker, ethanol (96 \%) F15 and dichloromethane from Brenntag Schweizerhall AG, diisopropylethylamine (DIPEA) was ordered from VWR and acetonitrile (ACN) from Fisher Scientific. BODIPY 630/650 was purchased from Invitrogen. Atto550-labeled, 22-mer Oligonucleotide (Atto550-ODN) (5' TAA CAG GAT TAG CAG AGC GAG G3') was obtained from Microsynth. Doxorubicin hydrochloride (DoxHCl) (98\%) was purchased from Beijing Zhongshuo Pharmaceutical Technology Development Co., Ltd. (China). DMEM, fetal bovine serum, Opti-MEM, and Penn/strep were obtained from Gibco. CellTiter 96® AQueous One Solution Cell Proliferation Assay (MTS) was purchased from Promega. FCCS standard double labeled DNA (488/633) was obtained from IBA (Göttingen, Germany). All other chemicals and reagents were ordered from Sigma-Aldrich. Free amines in DMF were eliminated by aluminum oxide prior to usage. Solvent exchange was performed in dialysis tubes from Spectrum Labs (Spectrum Laboratories, cellulose ester, MWCO 500-1000 Da, $3.2 \mathrm{~cm} / \mathrm{mL}$, wet in $0.05 \%$ sodium azide) using water from a Milli-Q ${ }^{\circledR}$ Direct 8 water purification system (Merck Millipore). 
Peptide synthesis and purification. All peptides were synthesized by solid phase peptide synthesis using a Syro I peptide synthesizer (MultiSyn Tech GmbH, Witten, Germany). AcX3gT was synthesized under the same conditions as previously published. ${ }^{40}$ The syntheses of the new $\mathrm{H} 3 \mathrm{gT}$ and H3SSgT peptides were performed at a $0.17 \mathrm{mmol}$ scale on a rink amide resin $(0.71$ $\mathrm{mmol} / \mathrm{g}$ reactive group concentrations) using standard fluorenylmethoxycarbonyl (Fmoc) chemistry and HCTU coupling protocols. At the end of the synthesis, the peptidyl resin was isolated and washed alternating with DMF, methanol, and dichloromethane. Cleavage from the resin and removal of protective groups was performed for $2 \mathrm{~h}$ in $10 \mathrm{~mL}$ containing $85 \%$ trifluoroacetic acid (TFA), 2.5\% triisopropylsilane, 2.5\% ethanedithiol, 5\% thioanisole and 5\% $\mathrm{H}_{2} \mathrm{O}$ for $\mathrm{H}_{3} \mathrm{SSgT}$ peptide, and a mixture of 95\% TFA, 2.5\% tetraethylsilane (TES), and 2.5\% water for H3gT peptide. The cleavage cocktail was filtered and the resin was washed additionally with $1 \mathrm{~mL}$ fresh cleavage cocktail. The filtrate was then precipitated in $40 \mathrm{~mL}$ cold diethylether (H3SSgT) or diisopropylether $(\mathrm{H} 3 \mathrm{gT})$ and then pelleted by centrifugation. The precipitated crude peptides were washed with cold diethylether or diisopropylether and dried. The peptides were solubilized with ACN and aqueous TFA (0.05\%, v/v) and lyophilized. Purification was carried out by HPLC (Shimadzu Prominence 20A, Japan) on a C18 reverse phase (RP) column (Merck Chromolith, RP-18e, $100 \mathrm{~mm}$ x $10 \mathrm{~mm}$ and $100 \mathrm{~mm}$ x $4.6 \mathrm{~mm}$ ) with mobile phases of water and acetonitrile containing $0.1 \%$ TFA while monitoring at $280 \mathrm{~nm}$ (gradient: 20\%-65\% ACN over $10 \mathrm{~min}$ ). The molecular mass was determined by liquid chromatography electron spray ionization mass spectrometry (LC-ESI-MS) using an LS instrument from Shimadzu, amaZon X MS from Bruker (Germany) with a water-acetonitrile gradient of $5 \%$ to $95 \% \mathrm{ACN}$ over $10 \mathrm{~min}$ (detection at $280 \mathrm{~nm}$ ). The mass was obtained in 
positive mode and referenced to parabene. Lyophilized peptides were stored in the freezer at $20^{\circ} \mathrm{C}$.

Peptide nanoparticle formation and characterization. To prepare peptide nanoparticles, peptides were dissolved in $50 \%$ ethanol to obtain $1 \mathrm{mg} / \mathrm{mL}$ stock solutions and filtered through $0.2 \mu \mathrm{m}$ hydrophilic syringe filters. Stock solutions were diluted to a concentration of $0.2 \mathrm{mg} / \mathrm{mL}$ using 50\% ethanol and subsequently dialyzed for approximately $16 \mathrm{~h}$ against water in prewashed 500-1000 MWCO dialysis tubes, renewing the exchange solvent twice. After removal of the samples from dialysis tubing, the size distribution was measured from diluted samples in water (1:10 v:v) by dynamic light scattering (DLS). DLS and zeta-potential data were carried out using a Zeta Sizer Nano ZSP (Malvern Instruments Ltd., UK) at a fixed angle of $\theta=173^{\circ}$ with a laser beam wavelength of $633 \mathrm{~nm}$ at room temperature. Transmission electron microscope (TEM) imaging was performed on a Philips CM100 TEM operating at an acceleration voltage of $80 \mathrm{kV}$. Samples were incubated for 2 min on hydrophilized, carbon coated, parlodion- $(2 \%$ in n-butyl acetate) copper grids, and when necessary were negatively stained with a $2 \%$ uranyl acetate solution (10 s incubation). SEM micrographs were taken on a Philips XL 30 ESEM operating at $5 \mathrm{kV}$. Samples were prepared on glass coverslips or mica and sputter-coated with silver or platinum. For Energy dispersive X-ray spectroscopy (EDX) analysis a FEI Nova NanoSEM was used operating at $10 \mathrm{kV}$. AFM profiles were obtained from a NanoWizard® III instrument from JPK Instruments AG using a PPP-NHCR cantilever (resonance frequency 204-497 kHz) and tapping mode in air. Confocal laser scanning micrographs (CLSM), fluorescence correlation spectroscopy (FCS) and fluorescence cross-correlation spectroscopy (FCCS) data were recorded on a commercial Confocor2 (Carl Zeiss, Jena, Germany), equipped with a laser diode (405 nm), 
an $\mathrm{Ar}+$ laser (514 nm), and two HeNe laser for $543 \mathrm{~nm}$ and $633 \mathrm{~nm}$, using a 40x C-Apochromat water immersion objective with a numeric aperture of 1.2.

Payload embedding. BODIPY 630/650 was diluted in dimethylsulfoxide (DMSO) to $1.5 \mathrm{mM}$, aliquoted and stored in the freezer at $-20^{\circ} \mathrm{C} .1 \mu \mathrm{L}$ of $1.5 \mathrm{mM}$ of bodipy was mixed with $100 \mu \mathrm{L}$ peptide stock solutions $(1 \mathrm{mg} / \mathrm{mL})$, diluted to $500 \mu \mathrm{L}$ with $50 \%$ ethanol and then dialyzed as described above. Atto550-AON-loaded peptide nanoparticles were prepared by addition of $4 \mu \mathrm{L}$ of $100 \mu \mathrm{M}$ Atto550-AON solution to $100 \mu \mathrm{L}$ peptide stock solutions $(1 \mathrm{mg} / \mathrm{mL})$ and diluted to $500 \mu \mathrm{L}$ with $35 \%$ ethanol. Then, the sample solution was dialyzed as described above. Coloading was performed by mixing $4 \mu \mathrm{L}$ of $100 \mu \mathrm{M}$ Atto550-AON with $1 \mu \mathrm{L}$ of $1.5 \mathrm{mM}$ BODIPY and $100 \mu \mathrm{L}$ of $1 \mathrm{mg} / \mathrm{mL}$ peptide, further diluted to $500 \mu \mathrm{L}$ with $35 \%$ ethanol and dialyzed. DoxHCl-peptide nanoparticles were prepared by adding $40 \mu \mathrm{L}$ of a $10 \mathrm{mM}$ DoxHCl solution in DMSO to $400 \mu \mathrm{L}$ peptide stock solution, then diluted to $2 \mathrm{~mL}$ with $50 \%$ ethanol, mixed and dialyzed as described above. DoxHCl-peptide nanoparticles were separated from nonembedded payload via three centrifugation/decantation cycles $\left(29700 \mathrm{RCF}\right.$ at $\left.5^{\circ} \mathrm{C}\right)$. Dox-loading was quantified by fluorescence (Perkin Elmer LS55 Luminescence Spectrometer, excitation wavelength: $490 \mathrm{~nm}$, emission wavelength: $555 \mathrm{~nm}$ ) using a standard dilution curve of DoxHCl. Loading of peptide nanoparticles with BODIPY, Atto550-AON was measured by fluorescence correlation spectroscopy (FCS). For BODIPY a HFT 633 / LP 650 filterset was used with a pinhole size of $90 \mu \mathrm{m}$ and a $633 \mathrm{~nm}$ laser with a laser power of 5\% while Atto550-AON was measured using a HFT 543 / LP 560 filterset with a pinhole size of $78 \mu \mathrm{m}$ and a $543 \mathrm{~nm}$ laser at $5 \%$ laser power. Loading was confirmed by confocal laser scanning microscopy (CLSM) for all three payloads: BODIPY, Atto550-AON and DoxHCl. For BODIPY a $633 \mathrm{~nm}$ laser at 10\% transmission was used with NFT 545 and LP 650 filters with a pinhole of $92 \mu \mathrm{m}$, Atto550-AON 
fluorescence was acquired using a $543 \mathrm{~nm}$ laser at 20\% transmission and HFT 488/543 and LP 560 filters with a pinhole of $78 \mu \mathrm{m}$. DoxHCl was detected using a $488 \mathrm{~nm}$ laser at $9.9 \%$ transmission with HFT 488, NFT 545, and LP 560 filters and a pinhole of $78 \mu \mathrm{m}$.

Release Experiments. Release experiments were performed by mixing $45 \mu \mathrm{L}$ of BODIPY- or AON-loaded peptide nanoparticles $(0.2 \mathrm{mg} / \mathrm{mL})$ with $5 \mu \mathrm{L}$ of $100 \mathrm{mM}$ dithiothreitol (DTT) dissolved in $100 \mathrm{mM}$ HEPES buffer at $\mathrm{pH} 7.2$ to obtain a $10 \mathrm{mM}$ DTT solution (DTT is stable in Hepes during the experiments time scale). As control experiments, loaded peptide nanoparticles were diluted with $100 \mathrm{mM}$ HEPES pH 7.2 to obtain $10 \mathrm{mM}$ buffer concentration. Samples were stirred at room temperature and at indicated time points $(2-120 \mathrm{~min}) 5 \mu \mathrm{L}$ aliquots were withdrawn and measured subsequently 15 x 5 s by FCS (see payload embedding section for instrument settings). FCS data was fitted with a two-component model, where component 1 was fixed to a free payload diffusion (about $61 \mu$ s for BODIPY and about $102 \mu$ s for Atto550-AON) (without triplet state), the structural parameter was fixed to 5. All release experiments were performed in triplicate with error bars representing the standard error. TEM micrographs after DTT treatment were obtained using above described conditions.

Characterization of BODIPY/AON co-loaded particles. Peptide nanoparticles were prepared as mentioned above. $5 \mu \mathrm{L}$ of nanoparticles were placed on a glass slide and micrographs were acquired right above the surface. CLSM micrographs were obtained using a HFT UV/488/543/633, NFT 545, LP 650, and BP 530-600 filterset with 9.9\% laser power and a pinhole of $82 \mu \mathrm{m}$ for the $633 \mathrm{~nm}$ laser and 16\% laser power and a pinhole of $76 \mu \mathrm{m}$ for the 543 $\mathrm{nm}$ laser. Images were processed and brightness profiles were obtained from the LSM image browser (Zeiss). FCCS data was recorded using HFT 514, LP 650, and BP 530-600 filters; a 514 $\mathrm{nm}$ laser at $20 \%$ transmission with a pinhole of $70 \mu \mathrm{m}$ and a $633 \mathrm{~nm}$ laser at $5 \%$ transmission 
with a $70 \mu \mathrm{m}$ pinhole. All data was fitted using a one-component model without triplet state and a structural parameter of 5 using ConfoCor3 software to obtain auto-correlation and the crosscorrelation functions:

$$
\mathrm{G}(\tau)_{\mathrm{fit}}=1+\frac{1}{N}\left[\frac{1}{1+\frac{\tau}{\tau_{\mathrm{D}}}} \frac{1}{\sqrt{1+R^{2} \frac{\tau}{\tau_{\mathrm{D}}}}}\right]
$$

$\tau_{D}$ is the diffusion time, $\mathrm{N}$ the number of particles, and $\mathrm{R}$ the structural parameter (was fixed to 5). Relative cross-correlation amplitudes (RCA) were calculated using the cross-correlation amplitude $G_{x}(0)$ and the auto correlation amplitudes of the Atto550-AON and BODIPY channel $\mathrm{G}_{\mathrm{AON}, \mathrm{BODIPY}}(0)$, respectively:

$$
R C A=\frac{G_{A O N, B O D I P Y}(0)-1}{G_{x}(0)-1}
$$

The co-loading degree (CLD) was calculated by normalizing the data where the minimal crosscorrelation of a mixture of both payloads in solution was set to $0 \%$ and the maximal crosscorrelation from a double-labeled DNA standard (IBA standard) was set to $100 \%$.

Cell culture. HeLa cells were grown in Dulbecco's modified eagle medium (DMEM) with 10\% fetal bovine serum (FBS), 100 units $/ \mathrm{mL}$ penicillin and $100 \mu \mathrm{g} / \mathrm{mL}$ streptomycin and maintained at $37^{\circ} \mathrm{C}$ in $5 \% \mathrm{CO}_{2}$.

Cell viability assay. Cytotoxicity analysis was performed using the Promega CellTiter 96® AQueous Non-Radioactive Cell Proliferation (MTS) assay to determine the number of viable cells in culture. Triplicate or pentaplicate wells containing 2000-5000 HeLa cells were seeded in a 96-well plate $24 \mathrm{~h}$ prior to the experiment in order to achieve confluency at the time of analysis. $10 \mu \mathrm{L}$ of peptide nanoparticle solution were added to the cells to give final concentrations between $50-300 \mu \mathrm{g} / \mathrm{mL}$ or $25-1000 \mu \mathrm{g} / \mathrm{mL}$ and incubated for $24 \mathrm{~h}$ or $48 \mathrm{~h}$ at $37^{\circ} \mathrm{C}$ 
with $5 \% \mathrm{CO}_{2}$. MTS solution $(20 \mu \mathrm{L} /$ well $)$ was added to the cells and then incubated for $2 \mathrm{~h}$. Cell viability in each well was calculated by measuring the absorbance of the cell solution (cells and media containing the nanoparticles) mixed with MTS solution at $490 \mathrm{~nm}$ using a SpectraMax $\mathrm{M}^{\mathrm{e}}$ (Molecular Device) spectrometer with a plate reader, and data was normalized against cells incubated with PBS (100\% viability) and background subtracted with the absorbance from the MTS alone.

Cellular uptake. HeLa cells $\left(2 \times 10^{4}\right.$ cells per well) were seeded into an 8-well chamber $24 \mathrm{~h}$ prior to the experiment. After 24 hours, the cell culture media was replaced with Opti-MEM (130 $\mu \mathrm{L}$ ) followed by addition of $20 \mu \mathrm{L} 0.2 \mathrm{mg} / \mathrm{mL}$ peptide nanoparticles. After $4 \mathrm{~h}$ incubation, the cell culture medium was replaced with serum-containing media $(300 \mu \mathrm{L})$. The cells were then incubated for another $20 \mathrm{~h}$. For cell uptake with serum the medium supplemented with 10\% FBS was renewed prior to sample application. Prior to live cell imaging, the media was replaced by PBS and the cell nuclei were stained for 10 min with $1.6 \mu \mathrm{L}$ of a $50 \mu \mathrm{g} / \mathrm{mL}$ Hoechst 33342 solution in PBS. Cell imaging was performed by CLSM. The samples were excited at $405 \mathrm{~nm}$ (Hoechst 33342), $543 \mathrm{~nm}$ (for Atto550-AON), and $633 \mathrm{~nm}$ (for BODIPY) while collecting the emission after a BP 420-480 filter (Hoechst 33342), a BP 530-600 filter (Atto550-AON) and a LP 650 filter (BODIPY), respectively. Images were taken with the same acquisition settings for comparison purposes.

Flow cytometry analysis. HeLa cells $\left(7 \times 10^{4}\right.$ cells/well) were plated into 24 -well tissue culture plates 24 hours prior to the experiment. The cell culture media was replaced with serum-free media $(460 \mu \mathrm{L})$ and $40 \mu 10.2 \mathrm{mg} / \mathrm{mL}$ peptide nanoparticles were added. After $4 \mathrm{~h}$ incubation, the serum-free medium was carefully removed and replaced with $1 \mathrm{ml}$ of medium containing $10 \%$ FBS. The cells were then incubated another $20 \mathrm{~h}$. Cells were trypsinized with $200 \mu \mathrm{l}$ of trypsin 
for 10 minutes at $37{ }^{\circ} \mathrm{C}$ and $5 \% \mathrm{CO}_{2}$. Following trypsinization, $800 \mu \mathrm{PBS}$ were added to the cells, gently mixed by pipetting and transferred into $1.5 \mathrm{~mL}$ microcentrifuge tubes. Cells were then pelleted by centrifugation at $200 \mathrm{RCF}$ for five minutes. Subsequently, the media was aspirated and the pellet was re-suspended in $250 \mu \mathrm{l}$ PBS and put on ice. $6 \mu \mathrm{L}$ of $50 \mu \mathrm{g} / \mathrm{mL}$ stock solution of Hoechst 33342 were added to each sample. Immediately prior to FACS analysis, the cells were vortexed gently. FACS measurements of BODIPY-loaded nanoparticles were performed by measuring at least 30000 cells with a FACS Canto II (BD, USA), the cells were excited with lasers at $405 \mathrm{~nm}$ and $633 \mathrm{~nm}$, and the emitted light passed through a Band Pass 450/40 and 660/20 filters, respectively, before reaching the detector. FACS measurements of Atto550-AON-loaded nanoparticles were performed by measuring at least 30000 cells with a BD LSR Fortessa, the cells were excited with lasers at $405 \mathrm{~nm}, 488 \mathrm{~nm}$ and $561 \mathrm{~nm}$, the emitted light passed through Band Pass 450/50, 542/27 and 586/15 filters, respectively. The data were processed with FlowJo Vx (Tree Star, USA) and a fluorescence histogram of viable cells only was plotted or the mean fluorescence intensity was extracted.

\section{RESULTS AND DISCUSSION}

\section{Design, synthesis, and characterization of peptides and their self-assemblies}

Two new amphiphilic peptides, H3gT and H3SSgT, were designed from the previously reported peptide, AcX3gT (Figure 2A). The first, H3gT, was designed with the cationic histidine amino acids in place of the acetylated lysines in order to improve the encapsulation of charged species such as AONs into the self-assembled nanoparticles (Figure 2B). In order to improve the release of cargo molecules from $\mathrm{H} 3 \mathrm{gT}$ nanoparticles, a second peptide $\mathrm{H} 3 \mathrm{SSgT}$ was designed by incorporating an artificial disulfide amino acid to serve as a reduction cleavable linker (Figure 


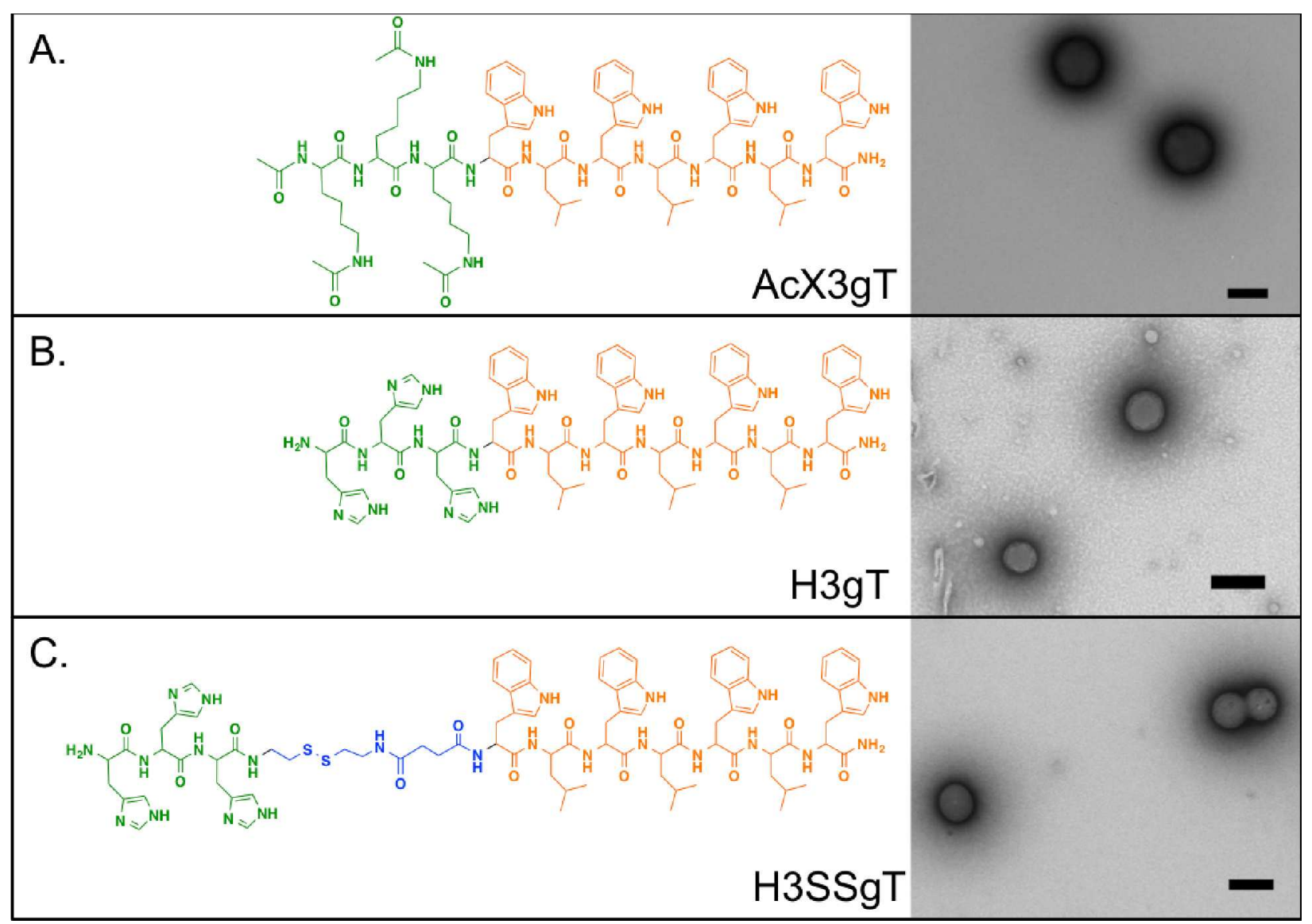


Figure 2. Synthesized peptide sequences of AcX3gT (A) ${ }^{40}$, H3gT (B), and H3SSgT (C). The hydrophobic gT sequence is orange, the hydrophilic sequence is green, and the reducible S-S linker is blue. TEM micrographs represent self-assembled structures of each peptide. Scale bar: $200 \mathrm{~nm}$.

Similar to AcX3gT, both H3gT and H3SSgT self-assembled in water leading to spherical nanoparticles. The change in the sequence from acetylated lysines of AcX3gT to oligo histidine of $\mathrm{H} 3 \mathrm{gT}$ or $\mathrm{H} 3 \mathrm{SSgT}$ did not affect the assembly properties of the amphiphilic peptides, revealing spherical shapes and a smooth surface by transmission electron microscopy (TEM) (Figure 2). However, the initial concentration of each peptide led to differences in nanoparticle size. For AcX3gT, there is a linear relation between initial concentration and nanoparticle size, with a lower plateau at $260 \mathrm{~nm}$ for concentrations below $0.5 \mathrm{mg} / \mathrm{mL}^{35}$ In contrast, $\mathrm{H} 3 \mathrm{gT}$ and $\mathrm{H} 3 \mathrm{SSgT}$ exhibited sizes of about $200 \mathrm{~nm}$ for nanoparticles assembled from peptide concentrations of 0.2 $\mathrm{mg} / \mathrm{mL}$. This is regarded as optimal size for drug delivery systems to have sufficient loading and good cell uptake ${ }^{58}$ but still avoid excessive clearance by macrophages ${ }^{4,59}$. Replacing acetylated lysines of AcX3gT with histidines of $\mathrm{H} 3 \mathrm{gT}$ did not alter the ability to form spherical nanoparticles in contrast to non-acetylated analogs of AcX3gT (K3gT). ${ }^{35}$ This can be attributed to a closer proximity between the side chain functional groups and its aromatic nature, which enables $\pi$ - $\pi$-stacking, cation- $\pi$ interactions and hydrogen- $\pi$ interactions ${ }^{60}$.

\section{Encapsulation of payload and characterization of loaded nanoparticles}

The ability of the new peptides $\mathrm{H} 3 \mathrm{gT}$ and H3SSgT to embed payloads was compared to AcX3gT using a hydrophobic small drug molecule model (BODIPY), or an Atto550 labeled antisense oligonucleotide (AON). First, fluorescence correlation spectroscopy (FCS), which 
distinguishes fluorescent species diffusing free in solution compared to those associated with nanoparticles, was measured to ensure the new peptides maintained the ability to load hydrophobic payloads. Varying the peptide sequence to include histidines or a reduction sensitive linker did not affect the incorporation of the hydrophobic molecule BODIPY (Table 1). AcX3gT and H3SSgT showed high loading efficiencies, however, upon encapsulating BODIPY in H3gT nanoparticles, the particles quickly shifted to large aggregates, which cannot be measured by FCS. The ratio of loaded cargo was obtained by fitting the autocorrelation functions using two component fits: free dye and dye-loaded peptide nanoparticles (Table 1). Next, AONs were loaded into each peptide nanoparticle. By FCS, AcX3gT showed a correlation curve identical to that of the free AON (Figure 3A). This indicated that AcX3gT was incapable of binding AONs due to a lack of charge interactions. However, both the H3gT and H3SSgT, which contain the oligo histidine sequence, were able to bind AONs showing an increased diffusion time compared to free AON alone (Figure 3A, Table 1). In contrast, the effective drug embedding efficiency of DoxHCl (as a hydrophilic small molecule drug) to $\mathrm{H} 3 \mathrm{gT}$ and $\mathrm{H} 3 \mathrm{SSgT}$ was determined to be $1.5 \mathrm{mg} / \mathrm{g}$ and $2.3 \mathrm{mg} / \mathrm{g}$ by fluorescence emission. The low embedding efficiencies resulted due to the hydrophilicity of $\mathrm{DoxHCl}$, thus lacking entropic driving forces in contrast to hydrophobic payloads. Due to the inability of AcX3gT to bind AONs and the formation of large nanoparticles when H3gT encapsulates BODIPY, we will further focus on $\mathrm{H} 3 \mathrm{SSgT}$ with the other two peptides being analyzed for comparison when appropriate.

Table 1. FCS characterization of singly and co-loaded peptide nanoparticles. Data represents average $\pm \mathrm{SD}(\mathrm{n}=3)$. *Two components model fit of the autocorrelation function.

\begin{tabular}{|l|l|l|l|l|}
\hline Peptide & Payload & Diffusion & Hydrodynamic & $\begin{array}{l}\text { Loading } \\
\text { efficiency* }\end{array}$ \\
\hline
\end{tabular}




\begin{tabular}{|c|c|c|c|c|}
\hline Nanoparticles & & $\begin{array}{l}\text { Time } \\
(\mu \mathrm{s})\end{array}$ & Diameter (nm) & $(\%)$ \\
\hline \multirow{2}{*}{ Free species } & BODIPY & $61.0 \pm 2.8$ & $\mathrm{~N} / \mathrm{A}$ & $\mathrm{N} / \mathrm{A}$ \\
\hline & $\mathrm{AON}$ & $102.0 \pm 7.3$ & $\mathrm{~N} / \mathrm{A}$ & $\mathrm{N} / \mathrm{A}$ \\
\hline \multirow{2}{*}{ AcX3gT } & BODIPY & $7700 \pm 440$ & $174 \pm 10$ & $82 \pm 7$ \\
\hline & $\mathrm{AON}$ & $\mathrm{N} / \mathrm{A}$ & $\mathrm{N} / \mathrm{A}$ & $\mathrm{N} / \mathrm{A}$ \\
\hline \multirow{2}{*}{$\mathrm{H} 3 \mathrm{gT}$} & BODIPY & $\mathrm{N} / \mathrm{A}$ & $\mathrm{N} / \mathrm{A}$ & $\mathrm{N} / \mathrm{A}$ \\
\hline & $\mathrm{AON}$ & $8430 \pm 2400$ & $235 \pm 67$ & $89 \pm 3$ \\
\hline \multirow{2}{*}{ H3SSgT } & BODIPY & $4550 \pm 330$ & $103 \pm 8$ & $93 \pm 6$ \\
\hline & $\mathrm{AON}$ & $5640 \pm 390$ & $157 \pm 11$ & $99 \pm 1$ \\
\hline \multirow{2}{*}{$\begin{array}{l}\text { Co-loaded } \\
\text { H3SSgT }\end{array}$} & BODIPY & $4270 \pm 760$ & $96 \pm 17$ & $91 \pm 2$ \\
\hline & $\mathrm{AON}$ & $3230 \pm 640$ & $90 \pm 18$ & $90 \pm 3$ \\
\hline
\end{tabular}

The successful incorporation of BODIPY and AONs into H3SSgT nanoparticles was confirmed by confocal laser scanning microscope (CLSM) (Figure 3F-G). Even the low DoxHCl loading was approved by CLSM micrographs (Figure 3H). The size and morphology of the nanoparticles were measured by dynamic light scattering (DLS) and scanning electron microscopy (SEM), respectively (Figure 3 B, C-E) and was confirmed by atom force microscopy (AFM) for DoxHCl-loaded H3SSgT particles (Figure S2). For AON- and DoxHCl-loaded particles only marginal differences in size and morphology were detected revealing smooth surfaces by SEM and diameters of $135 \pm 22 \mathrm{~nm}$ and $165 \pm 40 \mathrm{~nm}$, respectively. In DLS the diameters have been obtained with the same order of magnitude (148 nm and $187 \mathrm{~nm}$, respectively; Figure 3, Table S1), the differences being related to drying effect in SEM measurements. Particles loaded with BODIPY preserved the size as AON-loaded nanoparticles (149 nm; Figure 3, Table S1), but smaller diameters and rougher surfaces were observed by SEM 
compared to non-loaded H3SSgT nanoparticles (Figure S3, Table S1). The difference in morphology of BODIPY-loaded particles can be attributed to hydrophobic interactions of BODIPY with the hydrophobic gT sequence of the peptide and the formation of intermolecular $\pi$ - $\pi$-stacking between BODIPY and tryptophan ${ }^{61}$ interfering with the self-assembly process. The smaller sizes for AON-loaded compared to non-loaded particles can be attributed to the charge interaction resulting in more compact assemblies. Further analysis of the AON loaded nanoparticles was also performed using energy dispersive X-ray spectroscopy (EDX) to identify the simultaneous presence of the sulfur in the linker and the phosphorus of the AON backbone. Indeed, both elements were detected in AON loaded nanoparticles while no phosphorus signal was observed for particles loaded with BODIPY (Figure S4). Also, zeta-potential analysis showed an optimal DNA to peptide ratio at $40 \mu \mathrm{g}$ AON/mg peptide where the surface charge approached from cationic, known to promote cell uptake ${ }^{62}$, towards neutral, known to decrease protein interactions and clearance (Figure S4). ${ }^{63}$ 

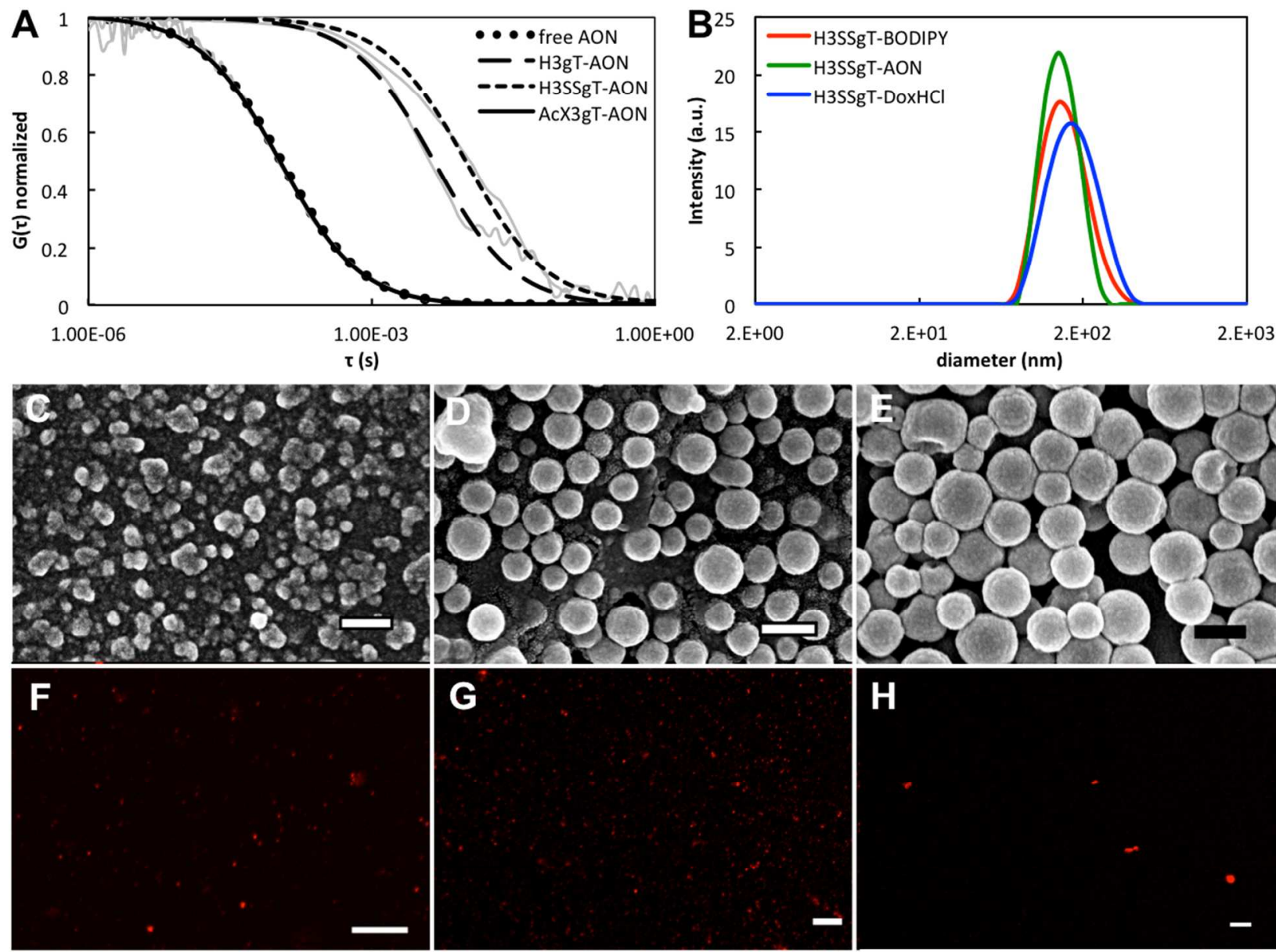

\section{H}

Figure 3. FCS autocorrelation curves (A) comparing free AON (dots) and AON complexed with AcX3gT (solid line), H3gT (broken line), and H3SSgT (dashes) nanoparticles. DLS data (B) for H3SSgT particles loaded with BODIPY (red), AON (green), and DoxHCl (blue). SEM and CLSM micrographs of H3SSgT nanoparticles loaded with BODIPY (C/F), AON (D/G), and DoxHCl (E/H). Scale bars for SEM micrographs are $200 \mathrm{~nm}(\mathrm{C}-\mathrm{E})$, and $10 \mu \mathrm{m}$ for CLSM micrographs $(\mathrm{F}-\mathrm{H})$.

$\underline{\text { Stimuli-responsive disintegration of peptidic nanoparticles and release of payload }}$ 
The implementation of a disulfide linker should allow H3SSgT nanoparticles to efficiently release loaded cargo molecules when exposed to physiological concentrations $(10 \mathrm{mM})$ of dithiothreitol (DTT) through reductive cleavage of the hydrophilic from the hydrophobic sequence. Liquid chromatography mass spectrometry (LC-MS) was used to detect the decomposition of $\mathrm{H} 3 \mathrm{SSgT}$ peptide before and after addition of reducing agent, corresponding to the full length peptide $\left([\mathrm{M}+2]^{2+}: 874.3 ;[\mathrm{M}+3]^{3+}:\right.$ 583.2) (Figure $\mathrm{S} 1 \mathrm{C}$ ) and the cleaved hydrophobic S-gT $\left([\mathrm{M}+1]^{+}: 1260.7 \mathrm{~m} / \mathrm{z} ;[\mathrm{M}+2]^{2+}: 630.8 \mathrm{~m} / \mathrm{z}\right)$ (Figure S1 D). The detection of the H3-S sequence was not found due to it having a drastically lower molar absorption at $280 \mathrm{~nm}$ compared to the tryptophans on the gT sequence and it being hidden in the baseline. Next, H3SSgT nanoparticles were investigated using TEM and SEM to visualize if the cleavage of the peptide led to subsequent destruction of the nanoparticles. After addition of DTT the micrographs showed decomposition of the spherical nanoparticles compared to H3SSgT nanoparticles without DTT (Figure 4). The smaller particles represent partly decomposed peptide nanoparticles due to the disintegration of the particles. The population with larger diameters suggests the aggregation of the cleaved hydrophobic gT sequence due to their instability in aqueous solution (Figure 4B). TEM micrographs and DLS indicate the coexistence of various stages of particle decomposition after DTT addition, ranging from intact peptide nanoparticles up to aggregates (Figure S5). AcX3gT and H3gT did not show particles decomposition when treated with DTT (Figure S6). 


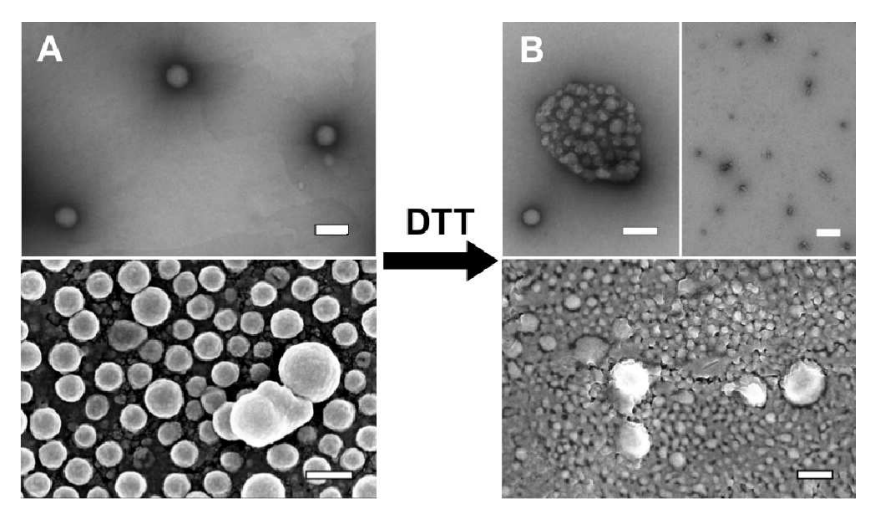

Figure 4. TEM (top) and SEM (bottom) micrographs of responsive H3SSgT nanoparticles before (A) and after treatment with DTT (B). Scale bars: $200 \mathrm{~nm}$.

FCS was then used to assess the simultaneous release of payload during particle decomposition. We selected BODIPY to be co-delivered with AON because it is appropriate as model molecule in terms of hydrophobicity and molecular weight, being in addition a fluorescent molecule easy to be detected by FCS. Due to the incompatibility of DoxHCl with FCS detection, it was not feasible to use this small molecule drug for these release assays. $10 \mathrm{mM}$ DTT was added to H3SSgT nanoparticles loaded with BODIPY or AON. Nanoparticles loaded with AON showed a fast release profile reaching approximately 50\% after 15 minutes, while with BODIPY $50 \%$ release was not achieved until 30 min (Figure 5). Fast release under reductive conditions while maintaining payloads, when incubated in buffer differentiate our system from slowly releasing, $\mathrm{pH}$-sensitive peptide nanoparticles showing a $\mathrm{pH} 5 / \mathrm{pH} 7.4$-release ratio of $2 .^{42}$ Similarly, our system is faster than amphiphilic peptides passively releasing hydrophobic payload from gene/drug co-loaded particles to $35 \%$ after $18 \mathrm{~h},{ }^{49}$ or $40 \%$ after $60 \mathrm{~h} .{ }^{50}$ Both BODIPY - and AON-nanoparticles showed almost complete disintegration by 120 minutes in the presence of DTT, with no release occurring without DTT (Figure 5). The slightly higher release 
rate of AONs can be associated to their hydrophilicity, positioning them on the outer hydrophilic corona of the individual micelles, whereas the hydrophobic payload is trapped in the micelles core, shielded by the hydrophilic part of the peptide. The release from H3SSgT in the presence of DTT was then compared with AcX3gT, for BODIPY loaded nanoparticles, or H3gT, for AON loaded nanoparticles. AcX3gT and H3gT, treated with DTT, did not result in an increased population of freely diffusing payload indicating no release (Figure 5).
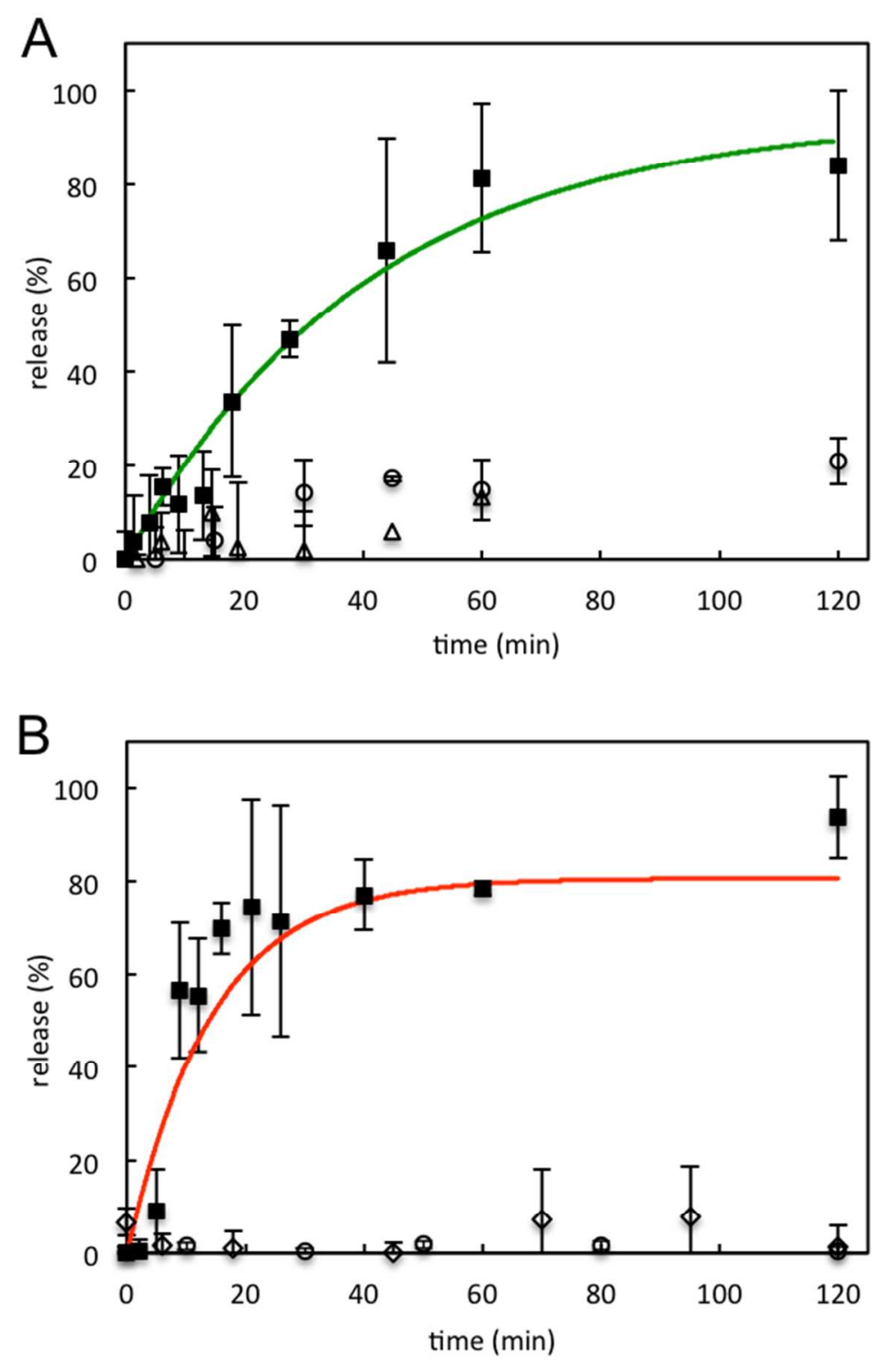
Figure 5. Release curves of BODIPY (A) or AON (B) loaded nanoparticles: squares represent H3SSgT+DTT, circles are H3SSgT-DTT, triangles are AcX3gT+DTT, and diamonds represent H3gT+DTT. Green and red lines are exponential fits of the H3SSgT data points using the Levenberg Marquardt algorithm. Data represents average \pm SD ( $n=3)$.

\section{Co-loading and combined release from $\mathrm{H} 3 \mathrm{SSgT}$ nanoparticles}

To assess the suitability of the stimuli-responsive H3SSgT nanoparticles to serve as multifunctional co-delivery carriers they were co-loaded with both AONs and BODIPY. The coloaded peptide nanoparticles were analyzed with CLSM to evaluate the simultaneous existence of both payloads in the particles (Figure 6A-C). An intensity profile through the micrograph indicated that not all particles are loaded equally (Figure 6D), but that most of the particles contained both AON and BODIPY. Fluorescence cross-correlation spectroscopy (FCCS) was used to quantify the fraction of co-loaded nanoparticles. FCCS is a dual-color variant of the FCS technique for the co-localization of two different fluorophores by cross-correlation of the individual channels ${ }^{64}$. All data were normalized with the free cargo mixture equaling $0 \%$ crosscorrelation and a standard double labeled DNA equaling $100 \%$ cross-correlation. It resulted in a calculated complete co-loading of the particles (Figure S7). To evaluate if the responsiveness was influenced by co-loading, co-release of both BODIPY and AON was compared by FCS to singly loaded nanoparticles. 50\% of BODIPY was released faster from co-loaded nanoparticles at around $10 \mathrm{~min}$ (Figure $6 \mathrm{E}$ ) compared to singly loaded ones ( $\approx 30 \mathrm{~min}$ ) (Figure $5 \mathrm{~A})$. This could be attributed to the additional interaction of both cargoes with the peptide, affecting the hydrophilic and hydrophobic interactions and potentially disturbing the assembly leading to less density within the nanoparticles, in contrast to peptide nanoparticles bearing only one type of 
guest molecules (Figure 5). The AON release behavior is almost congruent with singly loaded analogs due to different binding mode to the carrier.
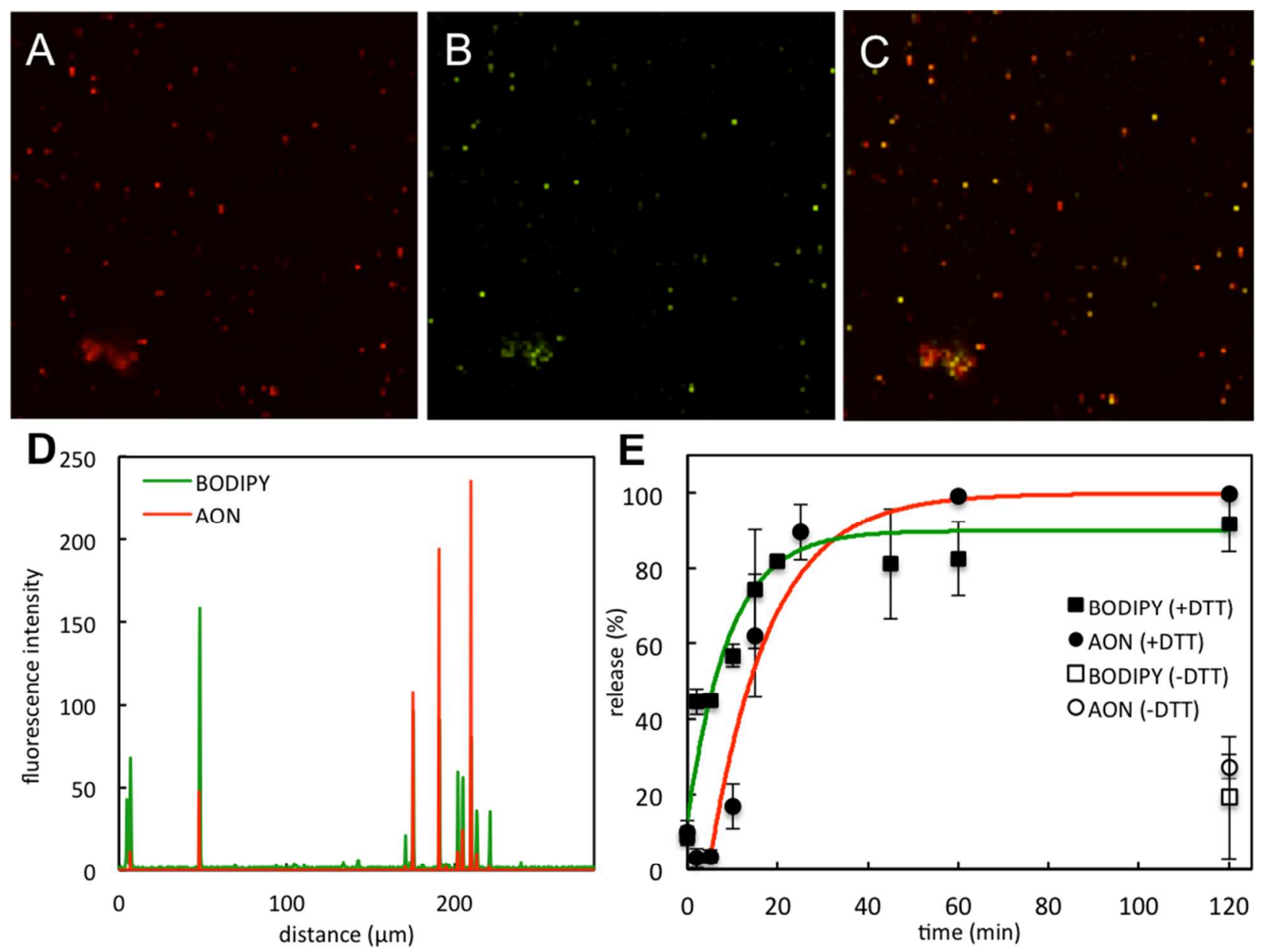

Figure 6. CLSM micrographs of AON (A, red channel) and BODIPY (B, green channel) coloaded H3SSgT nanoparticles (C, merged). Fluorescence intensity profile of a cross section of micrograph $\mathrm{C}$ (D). FCS release curve of BODIPY and AONs from co-loaded H3SSgT nanoparticles with DTT (E). Data represents average $\pm \operatorname{SD}(n=3)$.

\section{$\underline{\text { Cell uptake and anti-proliferation activity }}$}

The reduction sensitive $\mathrm{H} 3 \mathrm{SSgT}$ nanoparticles were evaluated for cytotoxicity to ensure the particles do not rapidly cause cell death. Peptide nanoparticles were non-toxic for concentration 
up to $1000 \mu \mathrm{g} / \mathrm{mL}$ at incubation times of $24 \mathrm{~h}$ and $48 \mathrm{~h}$ (Figure S8-A). Also, when the nanoparticles were treated with DTT prior to viability experiments the fragments did not show any toxicity after $48 \mathrm{~h}$ incubation (Figure S8-C). Cell toxicity for the free peptides could not be achieved due to the spontaneous self-assembly in aqueous media. Cell uptake and intra cellular behavior in HeLa cells were investigated with H3SSgT nanoparticles loaded with BODIPY or AON or co-loaded with both BODIPY and AON. Qualitative analysis of the cells by CLSM showed increased uptake for singly loaded (Figure S9 and S10) and co-loaded peptide nanoparticles with BODIPY (Figure 7A) and AON (Figure 7C). Cellular uptake was additionally demonstrated to be comparable for co-loaded particles when initially incubated in serumcontaining medium (Figure S12). The increased uptake to cells was subsequently quantified by fluorescence-assisted cell sorting (FACS) analysis. This resulted in a 10-fold higher uptake of embedded AONs compared to free AONs when equivalent AON concentrations were applied to the cells (Figure 7E). Free cargo as well as a mixture of BODIPY and AON (to ensure no cross interaction of molecules leading to uptake) did not show any detectable uptake (Figure S9-S11). This was expected for the negatively charged AON because it is commonly known that large anionic molecules do not internalize into cells. Free BODIPY is often shown to enter the cell, however, the amount of free BODIPY was the same as that in the particle solutions. At such low concentrations, free BODIPY was not enough to be seen by CLSM whereas when co-localized into peptide nanoparticles and more readily uptaken due to the positive surface charge, higher signals have been observed. 

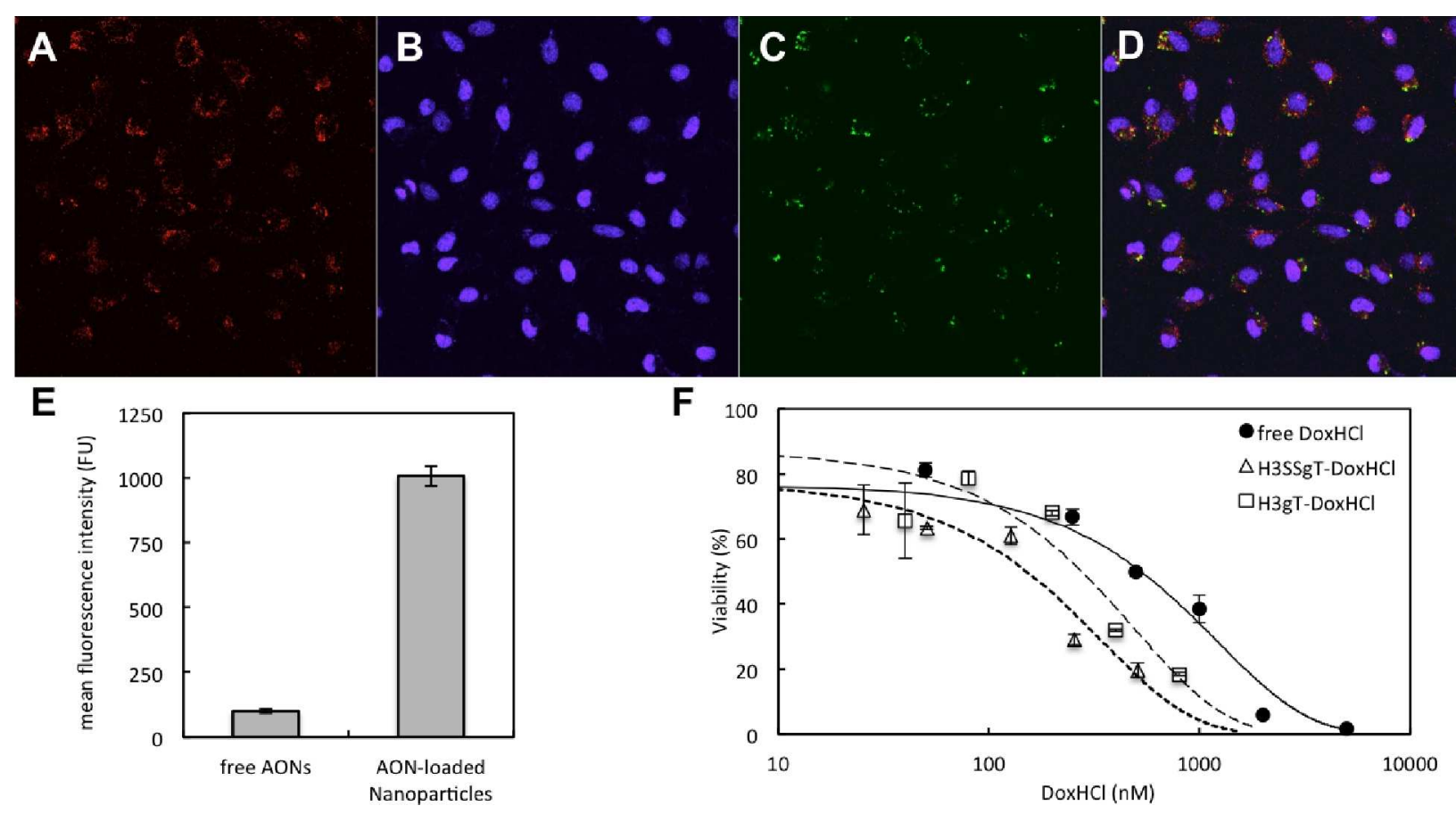

F

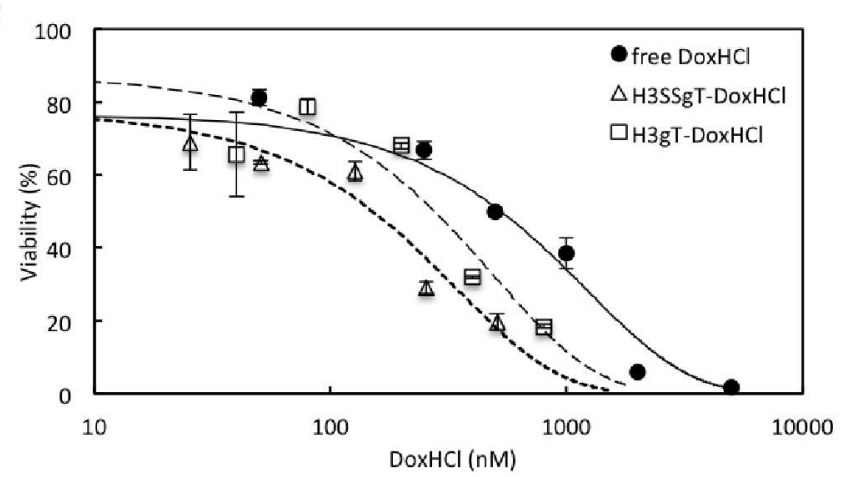

Figure 7. CLSM micrographs of co-loaded H3SSgT peptide nanoparticle accumulation in HeLa cells with BODIPY channel (A), Hoechst nucleus stain (B), AON channel (C), and merged (D). FACS data of cell uptake for AON loaded particles obtained from mean fluorescence intensities (E). Cell growth inhibition studies of free $\mathrm{DoxHCl}$, or DoxHCl loaded $\mathrm{H} 3 \mathrm{gT}$ and $\mathrm{H} 3 \mathrm{SSgT}$ peptide nanoparticles (F).

For subsequent cell growth inhibition studies only the $\mathrm{H} 3 \mathrm{gT}$ and $\mathrm{H} 3 \mathrm{SSgT}$ particles were loaded with hydrophilic DoxHCl to demonstrate the cell uptake and delivery qualities as well as the protection of the drug for more effectiveness. To assess the applicability of stimuliresponsive peptide nanoparticles as drug delivery system, DoxHCl was loaded into $\mathrm{H} 3 \mathrm{SSgT}$ nanoparticles and applied to HeLa cells. The IC50 value of DoxHCl-loaded peptide nanoparticles was determined for H3SSgT compared to free Dox (Figure 7F). The IC50 of DoxHCl loaded H3SSgT peptide nanoparticles (H3SSgT) was found to be $150 \mathrm{nM}$, approximately four-times lower than for free $\mathrm{DoxHCl}(530 \mathrm{nM})$. The decrease of IC50 is due to 
the hydrophilic character of DoxHCl, which has limited cell permeability compared to the nanoparticles. The decrease of IC50 value compared to free DoxHCl in HeLa cells is an indirect proof of DoxHCl release from nanoparticles upon uptake, and supports our system as a good candidate for co-delivery of small molecular weight molecules and AON. In addition, as the peptide fragments did not show any toxicity after $48 \mathrm{~h}$ incubation (Figure S8-C), we consider that the lower IC50 of DoxHCl loaded H3SSgT nanoparticles than DoxHCl loaded H3gT nanoparticles is the results of better DoxHCl release from $\mathrm{H} 3 \mathrm{SSgT}$ nanoparticles due to the $\mathrm{S}-\mathrm{S}$ breakage.

Also, when compared to the non-reducible DoxHCl loaded H3gT nanoparticles (280 nM), H3SSgT had an IC50 about two times lower. This difference demonstrates the influence of the added stimuli-responsive linker. H3gT nanoparticles are taken up by cells similarly to H3SSgT but do not rapidly or efficiently release the $\mathrm{DoxHCl}$, which is why the IC50 remains higher. The stimuli-responsive $\mathrm{H} 3 \mathrm{SSgT}$ particles reveal, in addition to a similar uptake performance compared to $\mathrm{H} 3 \mathrm{gT}$, a potent release mechanism allowing the drug to achieve its full potential. Endosomal escaping capacity of the nanoparticles will be evaluated in further experiments in conjunction with other more biologically relevant studies.

\section{CONCLUSION}

Development of non-toxic, biocompatible, and biodegradable nanocarriers for co-delivery and stimuli-responsive release of oligonucleotides and small drugs remains a remarkable challenge. We designed and synthesized responsive amphiphilic peptides, which assemble into peptide nanoparticles that were engineered to condense oligonucleotides via electrostatic interactions with histidine and to incorporate small molecules within their multicompartment micellar 
structure. The nanoparticles are able to carry hydrophobic and hydrophilic payloads as well as oligonucleotides, which can be released upon a physiological trigger. In addition, the histidines in the primary sequence support uptake to cells and subsequent proton sponge effect accelerating endosomal escape by its buffering capacity. Unlike most reported co-delivery systems, our stimuli-responsive nanoparticles are purely peptidic in nature and therefore intrinsically biodegradable. In contrast to the earlier reported peptidic co-delivery system based on Fmoclysine-histidine constructs revealing sizes of up to $550 \mathrm{~nm},{ }^{42}$ the diameter of the present nanoparticles match desired values for intravenous application. Furthermore, the implemented release mechanism is highly sensitive to a reduction potential in the cytosol to release co-loaded payloads with great efficiency. All of these characteristics make our peptide nanoparticles a promising candidate for co-delivery of multiple therapeutic payloads including hydrophobic Dox and plasmid DNA. Therefore, ongoing optimization experiments exploring the biocompatibility of these nanoparticles, their stability in animal blood serum and in vivo biodistribution and pharmacokinetic studies are planned to improve this system into a functional delivery system with high therapeutic effects.

\section{ASSOCIATED CONTENT}

Supporting Information Available. LC-MS, AFM, DLS, SEM, zeta-potential, EDX, FCCS, and CLSM data are provided (Figures S1-S12 and Table S1). This material is available free of charge via the Internet at http://pubs.acs.org.

\section{AUTHOR INFORMATION}

\section{Corresponding Author}

*E-mail: wolfgang.meier@unibas.ch 


\section{ACKNOWLEDGMENTS}

Financial support from SNSF, and NCCR are gratefully acknowledged. S.J.S thanks Gebert Rüf Stiftung „Peptide Targeted Transport System“ (GRS-048/11) and Freie akademische Gesellschaft Basel for fellowship. We thank Eva Bieler and Marcel Dueggelin for SEM and EDX measurements, Gianni Morson, Ursula Sauder, and Vesna Olivieri for assistance with TEM and the Zentrum for Microscopy Basel for access. Prof. Seebeck (Basel University) is acknowledged for access to the peptide synthesizer, and Dr. Gesine Gunkel-Grabole (Basel University) for AFM measurements. S.J.S. thanks Adrian Najer (Basel University) for help with FCS/FCCS and revising the manuscript, and Dr. Thomas Schuster for discussions.

\section{REFERENCES}

1. Gowda, R.; Jones, N. R.; Banerjee, S.; Robertson, G. P., Use of Nanotechnology to Develop Multi-Drug Inhibitors For Cancer Therapy. J. Nanomed. Nanotechnol. 2013, 4, (6), 184. 2. Margus, H.; Padari, K.; Pooga, M., Cell-penetrating peptides as versatile vehicles for oligonucleotide delivery. Mol. Ther. 2012, 20, (3), 525-533.

3. Aliabadi, H. M.; Landry, B.; Sun, C.; Tang, T.; Uludag, H., Supramolecular assemblies in functional siRNA delivery: where do we stand? Biomaterials 2012, 33, (8), 2546-2569.

4. Allen, T. M.; Cullis, P. R., Drug delivery systems: entering the mainstream. Science 2004, 303, (5665), 1818-1822.

5. Krishna, R.; Mayer, L. D., Multidrug resistance (MDR) in cancer: Mechanisms, reversal using modulators of MDR and the role of MDR modulators in influencing the pharmacokinetics of anticancer drugs. Eur. J. Pharm. Sci. 2000, 11, (4), 265-283.

6. Abbasi, M.; Lavasanifar, A.; Uludag, H., Recent attempts at RNAi-mediated P-

glycoprotein downregulation for reversal of multidrug resistance in cancer. Med. Res. Rev. 2013, $33,(1), 33-53$.

7. Doane, T.; Burda, C., Nanoparticle mediated non-covalent drug delivery. Adv. Drug Delivery Rev. 2013, 65, (5), 607-621.

8. Ming, X.; Laing, B., Bioconjugates for targeted delivery of therapeutic oligonucleotides. Adv. Drug Delivery Rev. 2015, 87, 81-89.

9. Järver, P.; Coursindel, T.; Andaloussi, S. E.; Godfrey, C.; Wood, M. J.; Gait, M. J., Peptide-mediated Cell and In Vivo Delivery of Antisense Oligonucleotides and siRNA. Mol. Ther. --Nucleic Acids 2012, 1, e27. 
10. Yu, Y. H.; Kim, E.; Park, D. E.; Shim, G.; Lee, S.; Kim, Y. B.; Kim, C. W.; Oh, Y. K., Cationic solid lipid nanoparticles for co-delivery of paclitaxel and siRNA. Eur. J. Pharm. Biopharm. 2012, 80, (2), 268-273.

11. Sun, X.; Pang, Z.; Ye, H.; Qiu, B.; Guo, L.; Li, J.; Ren, J.; Qian, Y.; Zhang, Q.; Chen, J.; Jiang, X., Co-delivery of pEGFP-hTRAIL and paclitaxel to brain glioma mediated by an angiopep-conjugated liposome. Biomaterials 2012, 33, (3), 916-924.

12. Cheng, D.; Cao, N.; Chen, J.; Yu, X.; Shuai, X., Multifunctional nanocarrier mediated codelivery of doxorubicin and siRNA for synergistic enhancement of glioma apoptosis in rat. Biomaterials 2012, 33, (4), 1170-1179.

13. Zhu, C.; Jung, S.; Luo, S.; Meng, F.; Zhu, X.; Park, T. G.; Zhong, Z., Co-delivery of siRNA and paclitaxel into cancer cells by biodegradable cationic micelles based on PDMAEMA-PCL-PDMAEMA triblock copolymers. Biomaterials 2010, 31, (8), 2408-2416. 14. Zhao, X.; Li, F.; Li, Y.; Wang, H.; Ren, H.; Chen, J.; Nie, G.; Hao, J., Co-delivery of HIF1alpha siRNA and gemcitabine via biocompatible lipid-polymer hybrid nanoparticles for effective treatment of pancreatic cancer. Biomaterials 2015, 46, 13-25.

15. Chu, D.; Xu, W.; Pan, R.; Chen, P., Co-delivery of drug nanoparticles and siRNA mediated by a modified cell penetrating peptide for inhibiting cancer cell proliferation. $R S C A d v$. 2015, 5, (26), 20554-20556.

16. Quan, C. Y.; Chen, J. X.; Wang, H. Y.; Li, C.; Chang, C.; Zhang, X. Z.; Zhuo, R. X., Core-shell nanosized assemblies mediated by the alpha-beta cyclodextrin dimer with a tumortriggered targeting property. ACS Nano 2010, 4, (7), 4211-4219.

17. Yuan, Y. Y.; Mao, C. Q.; Du, X. J.; Du, J. Z.; Wang, F.; Wang, J., Surface charge switchable nanoparticles based on zwitterionic polymer for enhanced drug delivery to tumor. Adv. Mater. (Weinheim, Ger.) 2012, 24, (40), 5476-5480.

18. Yang, X. Z.; Du, J. Z.; Dou, S.; Mao, C. Q.; Long, H. Y.; Wang, J., Sheddable ternary nanoparticles for tumor acidity-targeted siRNA delivery. ACS Nano 2012, 6, (1), 771-781.

19. Helmlinger, G.; Sckell, A.; Dellian, M.; Forbes, N. S.; Jain, R. K., Acid Production in Glycolysis-impaired Tumors Provides New Insights into Tumor Metabolism. Clin. Cancer Res. 2002, 8, (4), 1284-1291.

20. Danhier, F.; Feron, O.; Preat, V., To exploit the tumor microenvironment: Passive and active tumor targeting of nanocarriers for anti-cancer drug delivery. J. Controlled Release 2010, $148,(2), 135-146$.

21. Torchilin, V. P., Multifunctional, stimuli-sensitive nanoparticulate systems for drug delivery. Nat. Rev. Drug Discovery 2014, 13, (11), 813-827.

22. Li, Y.; Xiao, K.; Zhu, W.; Deng, W.; Lam, K. S., Stimuli-responsive cross-linked micelles for on-demand drug delivery against cancers. Adv. Drug Delivery Rev. 2014, 66, 58-73. 23. Jia, H. Z.; Zhang, W.; Zhu, J. Y.; Yang, B.; Chen, S.; Chen, G.; Zhao, Y. F.; Feng, J.; Zhang, X. Z., Hyperbranched-hyperbranched polymeric nanoassembly to mediate controllable co-delivery of siRNA and drug for synergistic tumor therapy. J. Controlled Release 2015, 216, 9-17.

24. Xiong, X.-B.; Lavasanifar, A., Traceable Multifunctional Micellar Nanocarriers for Cancer-Targeted Co-delivery of MDR-1 siRNA and Doxorubicin. ACS Nano 2011, 5, (6), 52025213.

25. Liu, S.; Guo, Y.; Huang, R.; Li, J.; Huang, S.; Kuang, Y.; Han, L.; Jiang, C., Gene and doxorubicin co-delivery system for targeting therapy of glioma. Biomaterials 2012, 33, (19), 4907-4916. 
26. Liu, C.; Liu, F.; Feng, L.; Li, M.; Zhang, J.; Zhang, N., The targeted co-delivery of DNA and doxorubicin to tumor cells via multifunctional PEI-PEG based nanoparticles. Biomaterials 2013, 34, (10), 2547-2564.

27. Yin, T.; Wang, L.; Yin, L.; Zhou, J.; Huo, M., Co-delivery of hydrophobic paclitaxel and hydrophilic AURKA specific siRNA by redox-sensitive micelles for effective treatment of breast cancer. Biomaterials 2015, 61, 10-25.

28. Gaspar, V. M.; Baril, P.; Costa, E. C.; de Melo-Diogo, D.; Foucher, F.; Queiroz, J. A.; Sousa, F.; Pichon, C.; Correia, I. J., Bioreducible poly(2-ethyl-2-oxazoline)-PLA-PEI-SS triblock copolymer micelles for co-delivery of DNA minicircles and Doxorubicin. J. Controlled Release 2015, 213, 175-191.

29. Wang, K.; Hu, Q.; Zhu, W.; Zhao, M.; Ping, Y.; Tang, G., Structure-Invertible Nanoparticles for Triggered Co-Delivery of Nucleic Acids and Hydrophobic Drugs for Combination Cancer Therapy. Adv. Funct. Mater. 2015, 25, (22), 3380-3392.

30. Han, L.; Tang, C.; Yin, C., Dual-targeting and pH/redox-responsive multi-layered nanocomplexes for smart co-delivery of doxorubicin and siRNA. Biomaterials 2015, 60, 42-52.

31. Rad-Malekshahi, M.; Visscher, K. M.; Rodrigues, J. P.; de Vries, R.; Hennink, W. E.; Baldus, M.; Bonvin, A. M.; Mastrobattista, E.; Weingarth, M., The Supramolecular Organization of a Peptide-Based Nanocarrier at High Molecular Detail. J. Am. Chem. Soc. 2015, 137, (24), 7775-7784.

32. Cui, H.; Webber, M. J.; Stupp, S. I., Self-assembly of peptide amphiphiles: from molecules to nanostructures to biomaterials. Biopolymers 2010, 94, (1), 1-18.

33. Hamley, I. W., Self-assembly of amphiphilic peptides. Soft Matter 2011, 7, (9), 4122.

34. Schuster, T. B.; de Bruyn Ouboter, D.; Palivan, C. G.; Meier, W., From fibers to micelles using point-mutated amphiphilic peptides. Langmuir 2011, 27, (8), 4578-4584.

35. Schuster, T. B.; de Bruyn Ouboter, D.; Bordignon, E.; Jeschke, G.; Meier, W., Reversible peptide particle formation using a mini amino acid sequence. Soft Matter 2010, 6, (21), 55965604.

36. van Hell, A. J.; Klymchenko, A.; Burgers, P. P.; Moret, E. E.; Jiskoot, W.; Hennink, W. E.; Crommelin, D. J. A.; Mastrobattista, E., Conformation and Intermolecular Interactions of SA2 Peptides Self-Assembled into Vesicles. J. Phys. Chem. B 2010, 114, (34), 11046-11052. 37. van Hell, A. J.; Costa, C. I. C. A.; Flesch, F. M.; Sutter, M.; Jiskoot, W.; Crommelin, D. J. A.; Hennink, W. E.; Mastrobattista, E., Self-Assembly of Recombinant Amphiphilic Oligopeptides into Vesicles. Biomacromolecules 2007, 8, (9), 2753-2761.

38. Korevaar, P. A.; Newcomb, C. J.; Meijer, E. W.; Stupp, S. I., Pathway selection in peptide amphiphile assembly. J. Am. Chem. Soc. 2014, 136, (24), 8540-8543.

39. de Bruyn Ouboter, D.; Schuster, T. B.; Sigg, S. J.; Meier, W. P., Self-assembled peptide beads used as a template for ordered gold nanoparticle superstructures. Colloids Surf., B 2013, $112,542-547$.

40. Dittrich, C.; Meier, W., Solid Peptide Nanoparticles - Structural Characterization and Quantification of Cargo Encapsulation. Macromol. Biosci. 2010, 10, (12), 1406-1415.

41. Shera, J. N.; Sun, X. S., Effect of Peptide Sequence on Surface Properties and SelfAssembly of an Amphiphilic pH-Responsive Peptide. Biomacromolecules 2009, 10, (9), 24462450 .

42. Han, K.; Chen, S.; Chen, W. H.; Lei, Q.; Liu, Y.; Zhuo, R. X.; Zhang, X. Z., Synergistic gene and drug tumor therapy using a chimeric peptide. Biomaterials 2013, 34, (19), 4680-4689. 
43. Liang, J.; Wu, W. L.; Xu, X. D.; Zhuo, R. X.; Zhang, X. Z., pH Responsive micelle selfassembled from a new amphiphilic peptide as anti-tumor drug carrier. Colloids Surf., B 2014, 114, 398-403.

44. Tang, Q.; Cao, B.; Wu, H.; Cheng, G., Selective gene delivery to cancer cells using an integrated cationic amphiphilic peptide. Langmuir 2012, 28, (46), 16126-16132.

45. Chen, J. X.; Xu, X. D.; Yang, S.; Yang, J.; Zhuo, R. X.; Zhang, X. Z., Self-assembled BolA-like amphiphilic peptides as viral-mimetic gene vectors for cancer cell targeted gene delivery. Macromol. Biosci. 2013, 13, (1), 84-92.

46. Rajpal; Mann, A.; Khanduri, R.; Naik, R. J.; Ganguli, M., Structural rearrangements and chemical modifications in known cell penetrating peptide strongly enhance DNA delivery efficiency. J. Controlled Release 2012, 157, (2), 260-271.

47. Mao, L.; Wang, H.; Tan, M.; Ou, L.; Kong, D.; Yang, Z., Conjugation of two complementary anti-cancer drugs confers molecular hydrogels as a co-delivery system. Chem. Commun. (Cambridge, U. K.) 2012, 48, (3), 395-397.

48. Guo, X. D.; Wiradharma, N.; Liu, S. Q.; Zhang, L. J.; Khan, M.; Qian, Y.; Yang, Y. Y., Oligomerized alpha-helical KALA peptides with pendant arms bearing cell-adhesion, DNAbinding and endosome-buffering domains as efficient gene transfection vectors. Biomaterials 2012, 33, (26), 6284-6291.

49. Wiradharma, N.; Tong, Y. W.; Yang, Y.-Y., Self-assembled oligopeptide nanostructures for co-delivery of drug and gene with synergistic therapeutic effect. Biomaterials 2009, 30, (17), 3100-3109.

50. Wiradharma, N.; Tong, Y. W.; Yang, Y.-Y., Design and Evaluation of Peptide Amphiphiles with Different Hydrophobic Blocks for Simultaneous Delivery of Drugs and Genes. Macromol. Rapid Commun. 2010, 31, (13), 1212-1217.

51. Kelkar, D. A.; Chattopadhyay, A., The gramicidin ion channel: a model membrane protein. Biochim. Biophys. Acta 2007, 1768, (9), 2011-2025.

52. Arndt, H.-D.; Vescovi, A.; Schrey, A.; Pfeifer, J. R.; Koert, U., Solution phase synthesis and purification of the minigramicidin ion channels and a succinyl-linked gramicidin.

Tetrahedron 2002, 58, (14), 2789-2801.

53. Schuster, T. B.; de Bruyn Ouboter, D.; Bruns, N.; Meier, W., Exploiting Dimerization of Purely Peptidic Amphiphiles to Form Vesicles. Small 2011, 7, (15), 2158-2162.

54. de Bruyn Ouboter, D.; Schuster, T. B.; Mantion, A.; Meier, W., Hierarchical Organization of Purely Peptidic Amphiphiles into Peptide Beads. J. Phys. Chem. C 2011, 115, (30), 14583-14590.

55. Cruz, C.; Santos, S. D.; Cabrita, E. J.; Queiroz, J. A., Binding analysis between Lhistidine immobilized and oligonucleotides by SPR and NMR. Int. J. Biol. Macromol. 2013, 56, 175-180.

56. Gunkel-Grabole, G.; Sigg, S.; Lomora, M.; Lörcher, S.; Palivan, C. G.; Meier, W. P., Polymeric 3D nano-architectures for transport and delivery of therapeutically relevant biomacromolecules. Biomater. Sci. 2015, 3, (1), 25-40.

57. Thielbeer, F.; Chankeshwara, S. V.; Johansson, E. M. V.; Norouzi, N.; Bradley, M., Palladium-mediated bioorthogonal conjugation of dual-functionalised nanoparticles and their cellular delivery. Chem. Sci. 2013, 4, (1), 425-431.

58. Hillaireau, H.; Couvreur, P., Nanocarriers' entry into the cell: relevance to drug delivery. Cell. Mol. Life Sci. 2009, 66, (17), 2873-2896. 
59. Hoyer, J.; Neundorf, I., Peptide Vectors for the Nonviral Delivery of Nucleic Acids. Acc. Chem. Res. 2012, 45, (7), 1048-1056.

60. Liao, S. M.; Du, Q. S.; Meng, J. Z.; Pang, Z. W.; Huang, R. B., The multiple roles of histidine in protein interactions. Chem. Cent. J. 2013, 7, (1), 44.

61. Yoshino, J.; Kano, N.; Kawashima, T., Fluorescent azobenzenes and aromatic aldimines featuring an N-B interaction. Dalton Trans. 2013, 42, (45), 15826-15834.

62. Yue, Z. G.; Wei, W.; Lv, P. P.; Yue, H.; Wang, L. Y.; Su, Z. G.; Ma, G. H., Surface charge affects cellular uptake and intracellular trafficking of chitosan-based nanoparticles. Biomacromolecules 2011, 12, (7), 2440-2446.

63. Chen, K.; Xu, J.; Luft, J. C.; Tian, S.; Raval, J. S.; DeSimone, J. M., Design of asymmetric particles containing a charged interior and a neutral surface charge: comparative study on in vivo circulation of polyelectrolyte microgels. J. Am. Chem. Soc. 2014, 136, (28), 9947-9952.

64. Bacia, K.; Kim, S. A.; Schwille, P., Fluorescence cross-correlation spectroscopy in living cells. Nat. Methods 2006, 3, (2), 83-89. 
For Table of Contents Use Only

\section{Stimuli-responsive co-delivery of oligonucleotides}

\section{and drugs by self-assembled peptide nanoparticles}

Severin J. Sigg, Viktoriia Postupalenko, Jason T. Duskey, Cornelia G. Palivan, Wolfgang Meier*

\section{TABLE OF CONTENTS GRAPHIC}

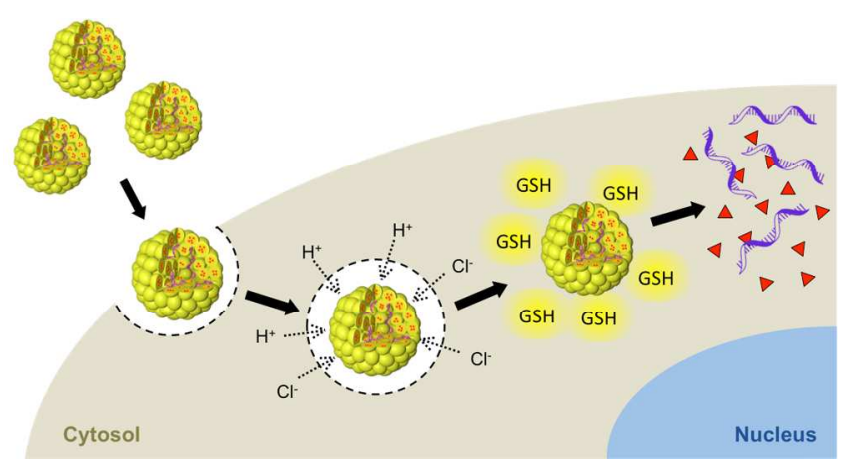

